ANUARIO DE Estudios MEdiEVAles 49/2, julio-diciembre de 2019, pp. 533-559

ISSN 0066-5061

https://doi.org/10.3989/aem.2019.49.2.06

\title{
REMENCES SENYORS DE REMENCES: LA FAMÍLIA TRIA D'ARENYS*
}

\section{REMENCES AS MASTERS OF REMENCES: THE TRIA FAMILY OF ARENYS}

\author{
GASPAR FELIU \\ Universitat de Barcelona - Institut d'Estudis Catalans \\ https://orcid.org/0000-0002-9191-0119
}

\begin{abstract}
Resum: La finalitat d'aquest article és estudiar l'evolució de la família Tria d'Arenys durant els tres darrers segles de l'Edat Mitjana. La característica principal d'aquesta família és que era una família de remences que a la vegada eren batlles jurisdiccionals i senyors de remences. L'existència de remences senyors de remences és coneguda des de ja fa alguns anys, però ha tingut una difusió escassa. L'article permet estudiar per primer cop l'evolució a llarg termini d'una família de pagesos benestants i la seva actuació com a remences, senyors de remences i batlles. La conclusió principal és que la remença no era una servitud clàssica, sinó una categoria jurídica: comportava càrregues servils i econòmiques, però no implicava cap tipus de segregació ni impedia l'enriquiment ni l'ascens social.
\end{abstract}

Paraules clau: Catalunya; Baixa Edat Mitjana; família; remences; batlles.

Abstract: The purpose of this article is to study the evolution of the Tria family, from Arenys, throughout the last three centuries of the Middle Ages. The main characteristic of this family is that it was a family of remences (a special class of Catalan serfs), that at the same time were jurisdictional bailiffs and masters of remences. The existence of remences that were at the same time masters of remences has been known for some years, but it has not been widely disseminated. The article makes it possible to study for the first time the long-term evolution of a family of wellto-do peasants and their performance as remences, as masters of remences, and as bailiffs. The main conclusion is that the remença was not a classic servitude, but a legal category: it carried servile and economic burdens, but it did not imply any kind of segregation or impede enrichment or social ascent.

Keywords: Catalonia; Late Medieval History; family; remences; bailiffs.

\section{SUMARI}

1. Introducció.- 2. La família Tria.- 3. Els Tria, remences i senyors de remences.4. Els Tria, batlles d'Arenys.- 5. Conclusions.- 6. Bibliografia citada.

\footnotetext{
* Aquest treball ha estat dut a terme dins del projecte "Producciones y espacios agrarios en sociedades ibéricas de la baja edad media. Estudios desde la arqueologia histórica (siglos XII-XVI)" (HAR2013-42195-P). Vull agrair a l'actual director de l'arxiu Fidel Fita, el Dr. Hug Palou, el seu ajut i les facilitats per la consulta dels pergamins originals.

Citation / Cómo citar este artículo: Feliu, Gaspar (2019), Remences senyors de remences: la família Tria d'Arenys, "Anuario de Estudios Medievales" 49/2,pp. 533-559. https://doi.org/10.3989/aem.2019.49.2.06

Copyright: (C) 2019 CSIC. This is an open-access article distributed under the terms of the Creative Commons Attribution 4.0 International (CC BY 4.0) License.
} 


\section{INTRODUCCIÓ ${ }^{1}$}

L'existència de remences senyors de remences va ser detectada per primera vegada per Freedman l'any $1991^{2}$ precisament en relació amb la família Tria, però amb el dubte de si només els remences que eren batlles podien tenir sota el seu domini altres remences. Després s'han conegut casos de remences que no eren batlles i que eren senyors d'altres remences, que Rosa Lluch ha recollit afegint-n'hi de nous ${ }^{3}$. Tot i això, que els remences podien ser a la vegada senyors de remences és una idea que encara malda per obrir-se pas, fins i tot entre els medievalistes; per això he cregut que valia la pena insistir-hi, aprofitant que disposem de documentació que permet seguir precisament aquesta família Tria d'Arenys ${ }^{4}$.

Convé recordar que els remences eren homes lliures que esdevenien serfs per raó de la terra que posseïen o que podien esperar posseir: tant com la terra era hereditària ho era igualment la servitud ${ }^{5}$. No cal ni puc fer aquí un resum de la situació dels pagesos de remença i de la seva lluita i de la bibliografia que ha generat; als efectes d'aquest treball n'hi ha prou amb remetre als dos llibres fonamentals de Jaume Vicenç Vives ${ }^{6}$ i als complements o matisacions posteriors de Freedman, Fernández Trabal, Lluch, Marcó, Ortí i To i de mi mateix ${ }^{7}$.

Com és prou sabut, els batlles eren oficials del senyor encarregats dels interessos d'aquest en una comunitat; podien ser jurisdiccionals, amb poders a la vegada de govern i econòmics o "de sac" si només tenien encarregada la funció recaptatòria. Els batlles jurisdiccionals cobraven els censos i agrers, exigien les prestacions en treball si n'hi havia, cobraven els lluïsmes, nome-

\footnotetext{
${ }^{1}$ Abreviatures utilitzades: perg. = pergamins de l'Arxiu Històric Fidel Fita d'Arenys de Mar; 11. $=$ lliures; $\mathrm{s} .=$ sous; $\mathrm{d} .=$ diners; $\mathrm{t} .=$ testament $++=$ mort $;+\mathrm{a} .=$ mort abans de

${ }^{2}$ En l'edició original anglesa de Freedman 1993,p. 167.

${ }^{3}$ Lluch 2014.

${ }^{4}$ L'arxiu històric municipal Fidel Fita d'Arenys de Mar conserva una gran quantitat de pergamins referents a la família Tria, inventariats en Pons i Guri 1984. Per evitar repeticions em referiré als pergamins de l'arxiu només com a (perg.) i el seu número d'ordre, que és el mateix que el de l'inventari publicat. L'arxiu conserva també documentació notarial i de la batllia, però per al present treball he utilitzat només el fons de pergamins.

${ }^{5}$ Això explica l'existència d'aquells remences fora del mas que tan bé ha documentat Lluch 2004: continuaven essent remences perquè no s'havien redimit i no ho havien fet per que no podien ser obligats a pagar la remença si no entraven sota una altra senyoria i per no perdre el dret a l'herència del mas en cas de manca de successors amb millors drets.

${ }^{6}$ Vicenç Vives 1945, 1954.

${ }^{7}$ Freedman 1993; Fernández Trabal 2002; Lluch 2004, 2005, 2014; Marcó 2008; Ortí, To 2014; Feliu, 2011.
} 
naven tutors, dirimien disputes i imposaven i cobraven multes si esqueia i passaven comptes amb el senyor, normalment un cop a $1^{\prime}$ any ${ }^{8}$. Per regla general eren triats entre els pagesos benestants de la localitat i sovint eren remences, bé perquè ja ho fossin bé perquè, rebessin un mas del senyor o ja el tinguessin, eren obligats pel seu càrrec a prestar jurament de fidelitat i homenatge $\mathrm{i} a$ comprometre's a no abandonar el mas.

La família Tria, propietària del mas Tria d'Arenys ${ }^{9}$ era una estirp de remences que segurament ja al segle XIII era a la vegada senyora de remences i que posseïa també en patrimoni la batllia jurisdiccional ${ }^{10} \mathrm{~d}^{\prime}$ Arenys pels Cabrera de la rama secundària dels senyors d'Anglès i Brunyola, que heretarien el vescomtat a l'extinció de la rama principal el $1328^{11}$. A la primera part examinaré l'evolució del llinatge, generació rere generació, tant l'aspecte pròpiament familiar com l'evolució econòmica del mas ${ }^{12}$; a la segona analitzaré el tema central de l'article, els Tria com a remences i senyors de remences, i a la tercera, els Tria com a batlles d'Arenys.

${ }^{8}$ Marcó 2008; Martínez Giralt 2012.

${ }^{9}$ Tria, sa Tria, de Tria, Trilla, sa Trilla, de Trilla, Tries o de Tries, que de totes aquestes formes apareixen els seus membres en els documents.

${ }^{10}$ Pons i Guri 1982, p. 15. A Arenys hi havia com a mínim una altra batllia, en mans de la família Sala, però era només una batllia dominical del monestir de Sant Pol. Sobre els diferents tipus de batllia, vegeu Benito 2012.

${ }^{11}$ Els Cabrera adquiriren la senyoria d'Arenys dels Montseny, senyors de la baronia de Montclús; per a la història de la senyoria d'Arenys es pot veure Pons i Guri, 1984a, pp. 11-12; 1989a; 1989b, en especial les pàgines 420, 426 i 439-440; Martínez Giralt 2012, pp. 16-19.

${ }^{12}$ Per a facilitar el seguiment del text, avantposo l'arbre genealògic de la família. Per cada persona figuren a l'arbre els anys de la primera i la darrera menció, així com l'any del casament (després del nom del membre del mas); la resta de dates van sota de cada nom amb les abreviatures assenyalades al començament, quan escauen. Les generacions estan indicades amb xifres romanes, que quan convé es repeteixen al text entre parèntesi, per a salvar les repetides homonímies. 


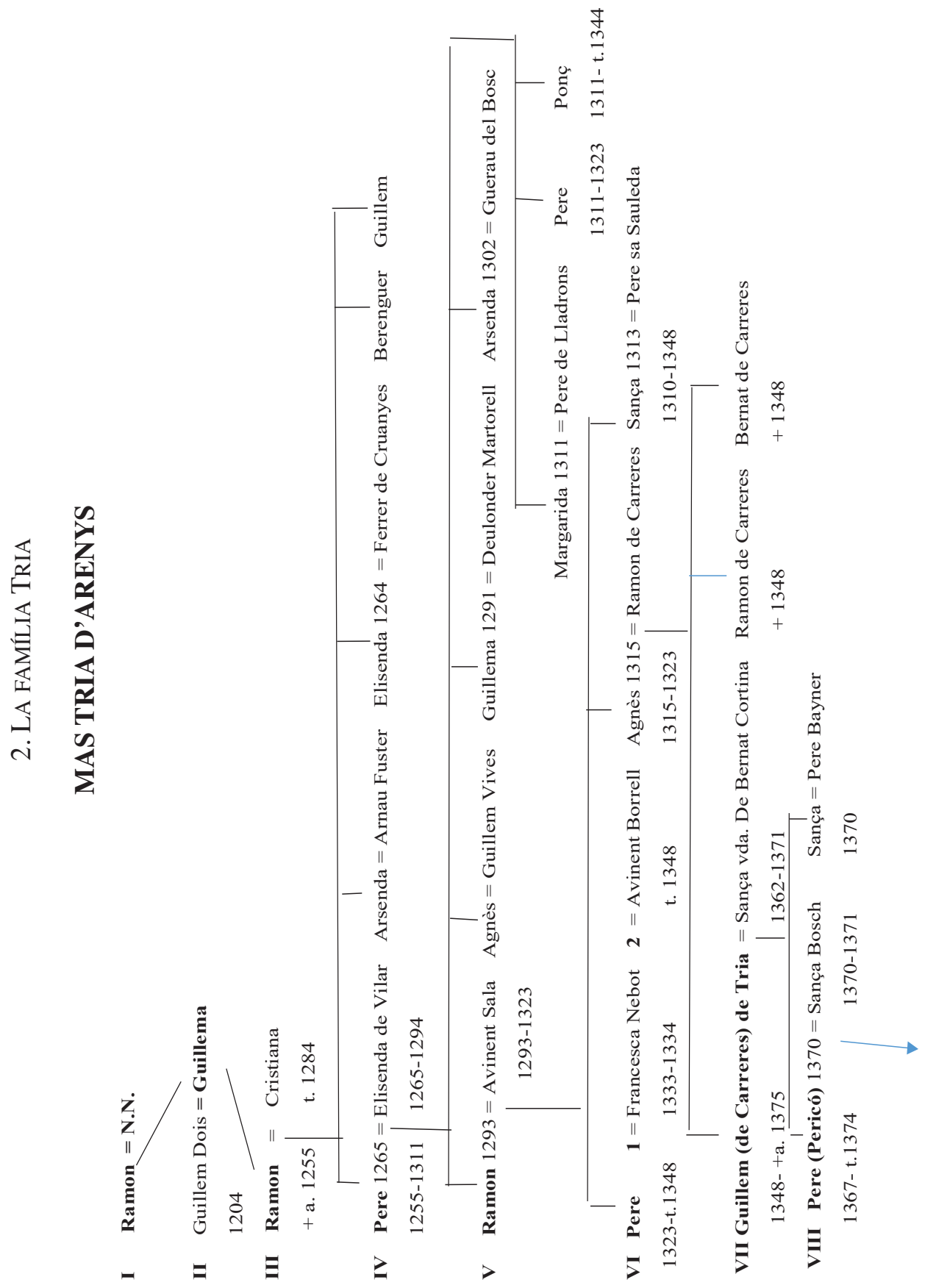




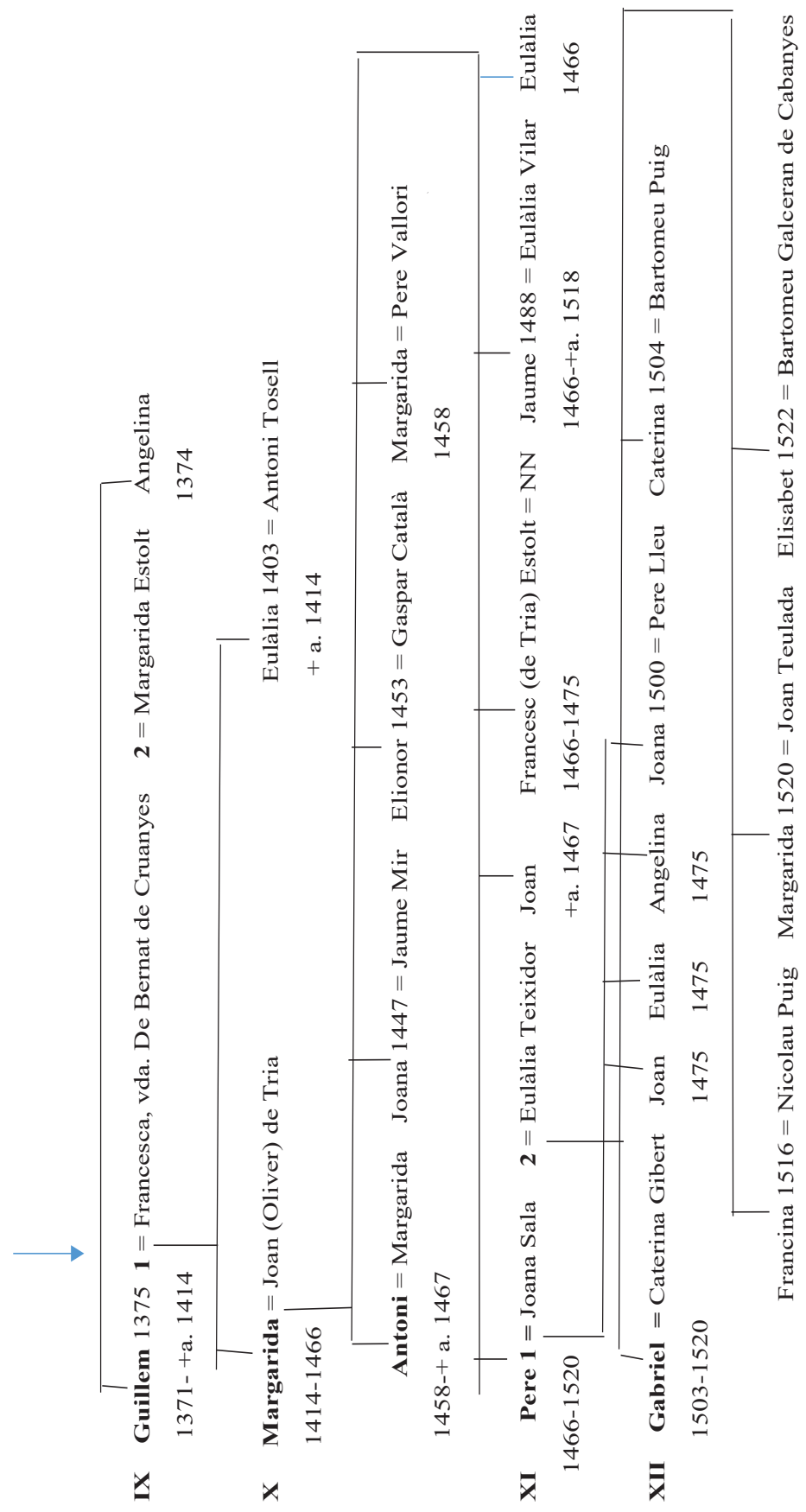


La primera referència coneguda del mas Tria d'Arenys és de l'any 1204 i correspon a un establiment o renovació d'establiment del mas Tria, que Guillem Umbert, senyor del Montseny, i la seva muller Raimunda feren als esposos Berenguer de Dois i Guillema (II), amb motiu del seu casament. Segons consta en el document, aquests reberen el mas tal i com l'havia tingut el difunt Ramon Tria (I) i el senyor va rebre a canvi 27 sous (perg. 42) ${ }^{13}$. El document es pot interpretar com un nou establiment, i en aquest cas el mas estaria en mans dels senyors a causa de la mort sense descendència de Ramon Tria, però aquesta interpretació requeriria que els nous emfiteutes (Berenguer Dois i Guillema) adoptessin el nom del mas. Com que a més a més el descendent i segurament fill de Berenguer i Guillema porta també el nom de Ramon Tria em sembla més probable que es tractés d'una renovació de l'establiment deguda al trencament de la successió masculina o fins i tot de la descendència directa. En aquest supòsit, Guillema seria filla o a tot estirar neboda del dit Ramon (I) i mare de Ramon (III); i el senyor requeriria una renovació remunerada de l'establiment emparant-se en el trencament de la successió masculina o directa. Tampoc no disposem de cap document que certifiqui que Ramon (III) era fill o parent de Guillem Dois, però de manera indirecta ho avala que la seva esposa Cristiana, en el seu testament nomenés marmessor un Bernat Dois, segurament oncle, cosí o nebot del seu espòs (perg. 120). Per tant m'inclino més aviat per acceptar la continuïtat familiar, de manera que el mas Tria existiria com a mínim des del darrer quart del segle XII. Fos com fos, a partir dels esposos Ramon Tria (III) i Cristiana tenim un coneixement continuat de la família fins més enllà de l'edat mitjana.

El primer document que coneixem del matrimoni de Ramon Tria (III) i Cristiana és l'obtenció d'un establiment que els féu l'any 1252 el monestir de Sant Pol de Mar. Es tracta de dos camps, situats en dos llocs diferents, que havien estat abans del mas Domingo, d'Arenys. A canvi els Tria van pagar al monestir 7 sous i mig d'entrada i com a cens anual la tasca i el braçatge de totes les collites (perg. 74) ${ }^{14}$. Que els camps que havien format part del mas Domingo fossin el 1252 propietat plena (alou) del monestir de Sant Pol voldria dir que el mas estava en aquest moment abandonat o que els seus tinents havien retornat aquests camps al monestir ${ }^{15}$.

\footnotetext{
${ }^{13}$ Tot i que les quantitats van expressades sovint en lliures, sous i diners, per a facilitar els càlculs he reduït gairebé sempre les lliures a sous.

${ }^{14}$ La tasca era un onzè i el braçatge un setzè, el conjunt sumava un 15,34 \% de la collita; amb el delme, reclamat per l'església, pujava a un 25,34\%.

${ }^{15} \mathrm{Al}$ cap de més d'un segle, l'any 1374, el mas Domingo estava poblat precisament per remences que es reconeixen homes propis del mas Tria (perg. 626 i 629); això fa suposar que les dues peces eren la major part del mas Domingo i que anys a venir els Tria van recompondre el
} 
Ramon (III) havia mort abans del 25 de novembre de 1255, data en que Cristiana féu hereu el fill Pere (IV) (perg. 76); Cristiana sobrevisqué com a mínim fins a 1284, any en el qual testà (perg. 120) ${ }^{16}$. Fills de Ramon i Cristiana foren, a més de l'hereu Pere, Arsenda, casada amb Arnau Fuster; Elisenda, casada l'any 1264 amb Ferrer Cruanyes, de Sant Cebrià de Vallalta (perg. 88); Berenguer i Guillem. Del dot d'Arsenda només en tenim notícia per una àpoca de l'any 1283 (perg. 118) per la qual la seva filla Guillema Costurer reconeixia al seu oncle Pere Tria (IV) que li havia pagat $300 \mathrm{~s}$. de doblenc que l'avi Ramon (III) havia llegat a Arsenda com a dot. No coneixem el dot d'Elisenda, però el seu marit li atorgà $1.400 \mathrm{~s}$. de tern entre donació pro nuptias i esponsalici (perg. 88), cosa que fa suposar que el dot venia a ser una quantitat semblant. ${ }^{17}$ La diferència dels dots de les dues germanes i el fet que el dot d'Arsenda no es liquidés fins gairebé 30 anys més tard de la mort del seu concessor m'inclinen a creure que els $300 \mathrm{~s}$. eren només un ròssec que havia quedat impagat i del qual es va haver de fer càrrec l'hereu Pere (IV), de manera que el dot de les dues germanes no devia ser tan diferent. Sí que ho era en canvi el dels cabalers: Berenguer i Guillem, romanien encara al mas l'any 1284, en el moment del testament de Cristiana, que repetia la deixa de $100 \mathrm{~s}$. per a cadascun, amb l'advertiment que si reclamaven més només rebrien 10 s. (perg. 120): els nois havien de tenir més de 30 anys i l'amenaça sembla indicar una situació familiar tibant.

Pere (IV) regentà el mas durant més de mig segle; es casà l'any 1265 amb Elisenda Vilar, que li aportà un dot de 1.470 s., als quals Pere n'afegí 730 propter nubcias (perg. 91). L'enllaç fou molt prolífic, atès se'n coneixen set fills adults: l'hereu Ramon (V), que es casà amb Avinent Sala (num. 140); Agnès, casada amb Guillem Vives, de Sant Iscle de Vallalta (perg. 211); Guillema, casada amb Deulonder Martorell, de Pineda (perg. 135 i 136); Arsenda, casada l'any $1302 \mathrm{amb}$ Guerau Bosch, de Sant Joan Sanata (perg. 171); i Margarida, casada amb Pere Lladrons, de Collsabadell (perg. 188); i dos cabalers, Pere i Ponç, els quals, com els seus oncles, reberen de llegítima $100 \mathrm{~s}$. cadascun (perg. 140). De Pere només sabem que vivia encara l'any 1323,

mas i el van subestablir amb la condició que els nous emfiteutes es fessin homes propis, solius i de remença seus i no pas del monestir (perg. 626 i 629).

${ }^{16}$ Els testaments de la família Tria s'ajusten molt als models presentats per Aventín 1996, pp. 539-588 i Richou, 2012 pp. 259-346, als quals remeto; em referiré només a alguns punts concrets. En el testament de Cristiana destaquen petites deixes (6 diners) a la catedral de Girona i al monestir de Montserrat; també llega $2 \mathrm{~s}$. a cada filla i una capa a Flaquera, possiblement una minyona o amiga.

${ }^{17}$ Per l'explicació i les característiques del dot, l'esponsalici i l'escreix o donació "propter nupcias" em remeto igualment a les pàgines que li dediquen Aventín 1996, pp. 459-520; Richou 2012, pp. 173-235. Afegiré només que els dots pagats semblen inferiors als del Vallès, Aventín 1996, però bastant superiors als de la vall d'Aro, Marcó 2008, p. 133; Ortí, To 2014, p. 187. 
quan l'esposa de Ramon (V), Avinent Sala en el seu testament llegà cinc sous a cadascun dels dos cabalers (perg. 281); de Ponç n'estem més ben informats, va fer fortuna i esdevingué ciutadà de Barcelona i en coneixem el testament, de l'any 1344 (perg. 404) ${ }^{18}$.

Desconeixem el dot d'Agnès; Guillema rebé 600 s. més béns mobles valorats en $200 \mathrm{~s}$. i el seu espòs Deulonder Martorell li otorgà 600 s. més d'escreix (perg. 136). Arsenda, casada onze anys més tard, tingué $850 \mathrm{~s}$. de dot, però no hi ha esment d'altres béns i en rebé 450 d'escreix (perg. 171). En canvi, Margarida es casà l'any 1308 amb un dot de 900 s., a més d'un vestit i un parament de llit (lectum pannorum $)^{19}$, dot al qual Pere Lladrons respongué amb $450 \mathrm{~s}$. d'esponsalici, assegurant aquestes quantitats sobre tot el seu mas i els seus béns i concedint-li la meitat de totes les compres que poguessin fer en el futur (perg. 188). Com es pot observar, els dots rebuts per les filles de Pere (IV) foren lleugerament ascendents, però en tot cas molt inferiors als $1.400 \mathrm{~s}$. que hem suposat a la generació anterior per Elisenda, esposa de Ferrer Cruanyes. Potser els temps eren més difícils, però també es podia tractar de la dificultat de dotar quatre filles en lloc de dues.

Elisenda, esposa de Pere (IV) testà l'any 1294 (perg. 143); a part de les donacions acostumades, deixà només cinc sous a cadascun dels fills $\mathrm{i}$ filles. Per la seva banda Pere testà el 1311 (perg. 211) i sabem que havia mort abans de febrer de 1312 (perg. 215); deixà 5 s. a cada filla, excepte a Guillema "Martorella" que en rebé sis, i $10 \mathrm{~s}$. als fills Pere i Ponç.

En l'aspecte econòmic, els Tria van passar en una generació de rebre establiments a crear i establir un mas: l'any 1295, Pere Tria (IV) amb el seu fill Ramon i l'esposa d'aquest Avinent establiren als esposos Guillem Soler i Guillema una peça de terra a Arenys per a construir-hi un mas, el qual haurien de tenir afocat, ells i els seus successors, al servei i fidelitat dels Tria, salvats els drets del senyor (Ramon de Cabrera). Els Soler s'obligaven a pagar $5 \mathrm{~s}$. d'entrada i un cens de mitja quartera de blat i un parell de gallines, a mes de la tasca i el braçatge de tots els esplets (perg. 148) ${ }^{20}$.

Fer un establiment i convertir-se així en senyors del domini directe i potser en senyors de remences (discutiré aquest punt en l'apartat 3) assenyala

${ }^{18}$ En el moment de testar, Ponç no esmenta esposa ni fills legítims; es declara parroquià de Sant Martí d'Arenys i ciutadà de Barcelona. Fa una deixa vitalícia a Alamanda Miró, segurament una amistançada, i llega petites quantitats a tres fills "pro amore Dei", frase que ve a ser una confessió de la seva il·legitimitat i per tant de la seva carència de drets; finalment, fa hereu universal el seu germà Ramon (V), o sigui el mas Tria.

${ }^{19}$ En què consistia el "lectum pannorum" o llit guarnit ho explica el dot de Joana (XII) de l'any 1500 (perg. 1278), en un paràgraf en català: "unum lectum gornit ço es un matalàs, un travaser, màrfaga, una flasada e un parell de lansolls".

${ }^{20}$ En aquest document apareix per primer cop Ramon de Trilla com a batlle. 
un important ascens social; no estic tan segur però de que fos també un ascens econòmic. Més aviat sembla que a començament del segle XIV els Tria anaven curts de diners: el 1312, mort Pere Tria, l'hereu Ramon (V) pagà $10 \mathrm{~s}$. que el seu pare devia a Jaume de Fontanills, de Sant Celoni (perg. 215), possiblement des d'anys abans, atès que també Fontanills havia mort i el cobrador era el seu hereu Jaume Torner; encara més, l'any següent, Ramon va pagar a Nicolau Mercer de l'Arbós 30 s. a compte d'un deute de 50 s. per compra de blat feta quatre anys abans. Els dots de les filles potser no van ser aliens a aquestes estretors, com veurem tot seguit.

Tornant a la família, l'any 1293 Pere (IV) i Elisenda havien fet hereu el fill Ramon (V) amb motiu del seu casament (perg. 140); e nom de l'esposa no apareix en el document, però consta que era Avinent Sala. Els pares es reservaven de per vida ser domini et potentissimi (senyors i majors) i, en cas que la convivència no fos possible, es retenien la meitat dels béns del mas i dels que aportés la futura esposa, a més d'una somada de vinya. Es reservaven a més $100 \mathrm{~s}$. cadascun per a testar i la mateixa quantitat per a pagar la llegítima de cadascun dels fills cabalers, mentre que els dots de les filles es deixaven a les possibilitats del mas ${ }^{21}$.

Durant els anys a cavall del segles XIII i XIV, el mas devia bullir de gent: Margarida, darrera filla de Pere i Elisenda, es casà l'any 1308; Sança, la primera del matrimoni de Ramon (V) i Avinent, ho féu el 1313 amb Pere Sauleda, de Sant Pere de Vilamajor, amb un dot de 1.500 s. i una caixa de núvia amb roba i paraments (perg. 207); el nuvi li correspongué amb un escreix de 750 s., la meitat del dot. Com veurem més endavant, amb motiu d'aquest casament es troba documentada per primer cop la condició de remences dels propietaris del mas Tria. Tot i haver-se casat abans, Sança no era la filla gran, sinó Agnès, que esposà l'any 1315 Ramon Carreres, de Sant Andreu de Bonaconjunta, al terme del castell del Far (perg. 279).

Els dots que reberen les filles de Ramon i Avinent són més d'una meitat més grans que els de la generació anterior; però sembla que els Tria van estirar més el braç que la màniga: els 200 darrers s. del dot de Sança no es pagaren fins a l'any 1315 (perg. 234) i pitjor encara, aquest darrer any Ramon (V) arribà a un acord amb Ramon Carreres per a rebaixar en 200 s. el dot ofert a la seva esposa Agnès (perg. 235); així i tot, el 1323 només se n'havien pagat $1.300 \mathrm{~s}$. i el dot no quedà pagat del tot fins a l'any 1329 (perg. 279 i 296). És molt possible que aquest desig d'aparentar estigués relacionat amb el casament de l'hereu, com veurem més endavant.

\footnotetext{
${ }^{21}$ De que tot plegat és un contracte en dóna bona fe que el document es fes per carta partida: així cada una de les parts en tenia una còpia.
} 
Avinent Sala, esposa de Ramon (V) testà l'any 1323. El pergamí que conté el testament (perg. 281) està ple de forats que impedeixen conèixer part del text; tot i això, ofereix algunes notícies sobre la família i l'economia del mas. Les deixes mostren un augment important respecte als testaments anteriors: Avinent llegà $50 \mathrm{~s}$. a la seva mare, $30 \mathrm{~s}$. a una germana, $10 \mathrm{~s}$. a una altra, $5 \mathrm{~s}$. a cadascun dels seus germans i $2 \mathrm{~s}$. a cada nebot o neboda, $5 \mathrm{~s}$. a una altra persona, segurament de l'entorn familiar i $2 \mathrm{~s}$. a la seva minyona, mentre que l'espòs Ramon rep $100 \mathrm{~s}^{22}$ També hi ha un augment de les deixes pietoses, que s'estenen fins al monestir de Montserrat, l'orde de la Mercè i una església de Girona ${ }^{23}$. Ramon la sobreviuria un quart de segle: encara vivia el 5 de juny de 1348, quan testà el seu fill Pere (IV), però havia mort abans del 26 d'octubre d'aquest any, quan consta que el mas havia passat a altres mans (perg. 428).

A la primera meitat del segle XIV, el mas Tria, que a més a més comptava amb els ingressos i el prestigi de la batllia, devia ser un dels principals masos de l'entorn. Ho demostra que l'hereu Pere (VI) es casés per damunt del seu entorn social. L'esposa, Francesca Nebot, d'Hostalric, pertanyia a una família prou rica per a imitar comportaments de la petita noblesa: el seu avi Ferrer Nebot havia fet construir i havia dotat un altar a l'església d'Hostalric ${ }^{24}$. No coneixem el dot aportat per Francesca, però disposava de 500 s. de lliure disposició a l'hora de testar, quantitat que acostumava a estar en relació amb el dot i que més que doblava la dels altres membres del mas Tria, que no sobrepassaven els $200 \mathrm{~s}$. El matrimoni durà poc i no tingué fills sobrevivents; el testament de Francesca (perg. 316) mostra el seu status: manà que el seu cos fos portat a Hostalric per a ser enterrat en el túmul dels seus avantpassats i repartí deixes molt superiors a les habituals: deixà $10 \mathrm{~s}$. a cada marmessor ${ }^{25}$ i $200 \mathrm{~s}$. al seu espòs; també féu deixes a dos altars de l'església i a l'hospital dels pobres d'Hostalric (20 s.), així com al seu pare i germans ( $5 \mathrm{~s}$. a cadascun), mentre que la seva germana rebé els seus vestits i la caixa de núvia amb el seu contingut; finalment féu hereu universal el seu germà segon $\mathrm{Arnau}^{26}$.

\footnotetext{
${ }^{22}$ Les gairebé segures deixes als fills s'han perdut per un forat del pergamí.

${ }^{23}$ Una altra vegada un forat en el pergamí impedeix de saber de quina església es tracta.

${ }^{24}$ L'altar i el presbiterat adjunt estaven dotats com a mínim amb una peça de terra a Santa Maria de Palautordera que Ferrer Nebot li havia traspassat en alou (perg. 366).

${ }^{25}$ Les deixes als marmessors són normalment de $2 \mathrm{~s}$. i en algun cas de 5; només Francesca Nebot els llega $10 \mathrm{~s}$.

${ }^{26}$ Aquest sembla un costum corrent entre les dones eixorques, ho veurem més endavant en parlar d'Avinent Borrell, esposa de Pere (VI); però com que el dot havia de tornar al mas d'origen, o sigui a l'hereu, el dubte és si a l'hereu universal li pertocava gran cosa.
} 
Pere (VI) esposà en segones núpcies Avinent Borrell, d'Arenys, que li aportà $1.300 \mathrm{~s}$. de $\operatorname{dot}^{27}$. Abans de continuar però amb la situació familiar, convé veure les poques dades disponibles sobre l'activitat econòmica del mas abans que la Pesta Negra ho trasbalsés tot. L'any 1333, Ramon Tria (V) amb l'hereu Pere i l'esposa d'aquest Francesca, va establir una peça de terra, prou gran com per crear un nou mas, que els Tria tenien sota el domini directe de Bernat II de Cabrera. Els beneficiaris, Bernat Tolosa i la seva esposa Saurina, es comprometien a pagar 28 s. d'entrada i 11 diners anuals de cens i a fer-se homes propis, solius i afocats, o sigui remences, dels Tria (perg. 314). L'any 1343, Pere Tria, amb consentiment del seu pare, va fer dos establiments emfitèutics semblants, (perg. 395 i 396) el primer als esposos Guillem Domingo i Elisenda, i el segon al matrimoni format per Bartomeu Lledó i Avinent; cadascuna de les parelles rebé en establiment una peça de terra, totes dues situades a la partida de Pla de Corts, terres que formaven part del cos o cub del mas Tria (sub censata mansi mei). La cessió es féu a la quarta part dels fruits, més elevada per tant que les cessions habituals a tasca i braçatge, però els receptors no estaven obligats a construir un mas ni a cap altra càrrega. Com que es tractava de terres obligades al pagament del cens al senyor eminent, l'operació exigí un acord amb aquest, l'esmentat Bernat II de Cabrera, que obtingué a canvi de la concessió un cens de dos sous cada any, que es deixarien de pagar però si els tinents abandonaven el conreu d'aquestes terres ${ }^{28}$.

La Pesta Negra s'endugué tots els membres de la família Tria. Davant la imminència de la Pesta o potser ja afectats per ella, els esposos Pere i Avinent van testar el mateix dia, el 5 de juny de 1348 (perg. 421 i 422). Els dos testaments són bastant semblants: a manca de fills, era cridat hereu el nebot Ramon Carreres, fill segon d'Agnès, germana de Pere (VI ${ }^{29}$, substituït si calia pels seus germans, l'un darrera l'altre, el més gran que no fos casat. En els seu defecte serien cridats els fills de l'altra germana, Sança Sauleda i en darrer terme un fill del nebot Guillem Carreres, hereu del mas Carreres. Com que l'hereu no era un fill, els testadors van ser més generosos que de costum amb la seva ànima i el seu record. Les deixes per misses i almoines

\footnotetext{
${ }^{27} \mathrm{El}$ muntant del dot és conegut pel reconeixement que féu el seu germà Arnau Borrell; el retorn és féu com a mínim en tres terminis i no es completà fins a l'any 1355 (perg. 435 i 483).

${ }^{28}$ Ens trobem doncs davant de la "fam de terra", o sigui de l'excés relatiu de població que caracteritza l'època anterior a la Pesta Negra; la previsió de que la terra podia deixar de ser conreada mostra els dubtes sobre si l'establiment seria rendible.

${ }^{29}$ L'hereu no podia ser el fill gran, hereu del mas Carreres, atès que el mas Tria era de remença i per tant afocat.
} 
són semblants a les dels testaments anteriors de la família ${ }^{30}$, però tots dos innoven creant un aniversari amb missa i absolta, tot i que ho fan de manera diferent: Pere mana que l'hereu compri en el termini de quatre anys un censal que doni una pensió suficient per a sufragar aquest funeral i posa aquesta compra com a condició per a l'herència, mentre que Avinent fa una deixa de $240 \mathrm{~s}$. amb la mateixa finalitat. Ambdós es fan també mútuament una donació de 100 s. En canvi, Pere no fa deixes a cap familiar, mentre que Avinent es recorda de la mare, els germans, els nebots i dues persones més, una d'elles la seva criada, i nomena hereu el germà Bernat, que no ho era del mas Borrell: l'hereu d'aquest, Guillem, apareix entre els marmessors, però devia morir també a causa de l'epidèmia: les àpoques de retorn del dot d'Avinent les signà un altre germà, Arnau, en qui devia recaure el mas Borrell després de la pesta (perg. 483).

La peripècia del mas Tria ofereix un bon exemple de la mortaldat $i$ el desordre provocats per l'epidèmia: no només moriren totes les persones de la família del mas, sinó també l'hereu cridat, Ramon Carreres. El mas pervingué així al seu germà Bernat. Però per un document del 26 d'octubre de 1348 (perg. 428) sabem que Bernat permutà amb el seu germà Guillem, hereu del mas Carreres, les respectives possessions: Guillem obtenia així el mas Tria i Bernat el mas Carreres, a condició que Guillem pagués tots els deutes del mas Tria i de la batllia d'Arenys.

El mas Tria, amb l'afegit de la batllia d'Arenys, devia ser més valuós que el mas Carreres, però el cabaler segurament no disposava de prou diners per a fer front als deutes i despeses del mas i la batllia, cosa que sí que podia fer Guillem, hereu del mas Carreres. No coneixem el detall del deutes i obligacions del mas Tria, però com hem vist, el testament de Pere (VI) obligava l'hereu a comprar un censal, amb el qual finançar un aniversari perpetu; el seu cost no podia ser gaire inferior als $240 \mathrm{~s}$. que l'esposa Avinent havia destinat a la mateixa finalitat; a més a més, calia retornar els $1.300 \mathrm{~s}$. del dot d'Avinent Borrell, que havia mort sense fills, retorn que fou satisfet com a mínim en tres terminis entre 1350 i 1355 (perg. 435, 471 i 483). I encara el senyor devia exigir el pagament de l'eixorquia de Pere i Avinent, a part d'altres deutes que podien tenir tant el mas com la batllia. Pitjor encara, i potser només es tracta d'un cas entre altres, l'any 1354 Guillem Tria (VII) ${ }^{31}$ hagué d'acceptar reduir de 9 a 6 s. el cens que Guillem Terra li pagava per una feixa de terra que amenaçava amb abandonar si no li era concedida la reducció (perg. 477) ): a la

\footnotetext{
${ }^{30}$ A més de les deixes acostumades a l'església i les capelles d'Arenys, tots dos fan petits donatius a l'església de Caldes d'Estrac i al monestir de Montserrat; Avinent hi afegeix l'església de Santa Maria del castell d'Argimon.

${ }^{31}$ Com era costum, Guillem Carreres prengué immediatament el cognom de Tria.
} 
inversa del que passava abans de la pesta, aquesta havia convertit el treball i no la terra en el factor escàs i per tant car.

Així doncs, el mas Tria tingué en un any quatre propietaris: Pere (VI), Ramon Carreres, que segurament no arribà a prendre'n possessió, i els seus germans Bernat i Guillem (VII), que seria l'hereu definitiu i l'origen de la segona estirp del mas Tria. Guillem es casà amb Sança, vídua de Bernat Cortina (perg. 547), la qual li aportà 1.440 s. de dot, tot i que se'n feren constar més (perg. 602). Com veurem més endavant, temps a venir aquest casament provocaria que el mas Cortina passés a ser propietat del mas Tria. L'any 1362, Guillem Tria (VII) dotà la fillastra Valença Cortina, filla del primer matrimoni de Sança, amb 600 s. i la resta del parament acostumat en el moment del seu casament amb Francesc Forn, de Torrentbò (perg. 547). En canvi, una segona filla del mateix matrimoni, Avinent Cortina, va ser dotada directament per Sança l'any 1369, amb tot allò que havia rebut en herència dels seus sogres, Bernat Cortina i Esclaramonda, excepte el dot que Sança havia aportat al mas Tria $^{32}$; l'espòs d'Avinent, a qui tornarem a trobar més endavant, fou Arnau Cabanya, d'Arenys (perg. 805).

Els fills coneguts de Guillem Tria i Sança són l'hereu, Pere (VIII), anomenat sovint Pericó, casat el 1370 amb Sança Bosc (perg. 593), i Sança, casada amb Francesc Bayner de Sant Celoni (perg. 590) ${ }^{33}$. L'any 1367 Guillem (VII) emancipà i féu hereu Pericó, de només quinze anys (perg. 567 i 568), sense que en coneguem la raó. La hipòtesi més plausible és que Guillem s'hagués vist embolicat en les rebel-lions que es produïren al vescomtat després de l'execució de Bernat II de Cabrera l'any 1364³; amb la cessió, potser pactada, atès que es féu davant del veguer, Guillem aconseguiria que el mas i la batllia no es veiessin afectats per possibles represàlies contra ell.

La mala situació econòmica del mas en el moment posterior a la Pesta, que va provocar la renúncia del primer hereu, sembla que va millorar aviat; Guillem (VII) fou possiblement un home emprenedor: l'any 1370 el trobem passant comptes amb Pere Besó, d'Hostalric, pel mill que aquest li havia confiat per a vendre'l a Arenys (perg. 595). Però la millor demostració

\footnotetext{
${ }^{32}$ Aquest heretament és una mica sorprenent atès que Sança tenia de Bernat Cortina un fill mascle, de nom també Bernat, que era per tant l'hereu del mas Cortina. Potser Bernat tenia algun defecte que i li impedia fer-se càrrec de la gestió del mas? En tot cas no estava impedit ni per a negociar ni per a testar: en el seu testament de 1271 (perg. 612) es mostra com una persona relativament acabalada: deixa a la germana Avinent 5 florins (55 s.) i totes les robes de la botiga i 5 florins més a la neboda Valençó Sauleda (filla segurament de la germana Valença) i 44 s. per l'almoina del pa, si bé totes aquestes quantitats s'havien de cobrar de deutors; i nomena hereva universal la seva mare.

${ }^{33}$ D'aquest matrimoni només en tenim notícia per una àpoca de l'any 1370 per la qual Francesc Bayner confessa haver rebut com a part del dot promès $165 \mathrm{~s}$. i un vestit.

${ }^{34}$ Pons i Guri 2002, p. 13.
} 
del canvi de conjuntura és sens dubte que Guillem va fer fer i va pagar les portes del cementiri d'Arenys, cosa que va fer constar amb orgull en el seu testament (perg. 602).

Els esposos Guillem Tria (VII) i Sança, i també l'esposa de l'hereu Pericó, Sança Bosch, testaren el mateix dia, el 8 d'abril de 1371 (perg. 602, 603 i 604). En el seu testament, Guillem fa una deixa de 20 s. a la filla Sança (Bayner) i una altra de $10 \mathrm{~s}$. a la fillastra Avinent (Cabanya) i llega $5 \mathrm{~s}$. a cadascun dels seus germans (perg. 602). En canvi, sembla que hi hagué un estira i arronsa entre ell i la seva esposa, que rebé només $10 \mathrm{~s}$. amb l'excusa que ja era prou, vist el que li quedava a l'hereu; en tot cas, en el testament de Sança no hi ha cap llegat per a l'espòs, només deixes als fills del primer marit i als néts. Al seu torn, Sança Bosch fa deixes a la mare Alamanda i als germans i també al marit, totes elles de $5 \mathrm{~s}$., i nomena hereu el prenyat que porta $\mathrm{i}$, si mor sense fills, el marit (perg. 603). Possiblement es va cridar el notari davant d'un part de Sança Bosch que es podia presentar difícil i l'ocasió va ser aprofitada pels seus sogres per a testar també ells; a no ser que el desencadenant de tot plegat no fos la pesta d'aquest any. Aquests testaments es van demostrar prematurs; potser sí que va morir aviat Sança Cortina, de qui no en sabem res més, però tant Guillem (VII) com la seva nora Sança Bosch vivien encara l'any 1374 (doc. 632).

Del matrimoni de Pericó i Sança, en coneixem només dos fills, l'hereu Guillem i Angelina, que segurament eren molt joves el 1374, quan en el seu testament Pericó deixà dit que la noia fos dotada segons les capacitats del mas (perg. 632); aquesta és l'única notícia que tenim d'Angelina. A més Pericó féu deixes de $10 \mathrm{~s}$. al pare, a la germanastra Avinent Cabanya i a la muller Sança, a qui deixa senyora i majora i usufructuària, a condició de mantenir-se vídua (casta et sine viro), i finalment nomenà hereu el fill Guillem. Aquest era però encara massa jove per a fer-se càrrec del mas, de manera que va ser posat sota la tutoria d'un membre de la família Sala, d'Arenys, cal suposar que després de la mort dels pares i de l'avi Guillem (VII) ${ }^{35}$.

Guillem (IX) devia tenir ben just quinze anys quan es casà l'any 1375 amb Francesca, vídua de Bernat Cruanyes, de Sant Cebrià de Vallalta, la qual li aportà un dot de 500 s. (perg. 642). Més tard el trobem casat amb Margarida

\footnotetext{
${ }^{35}$ Aquesta tutoria havia de ser molt curta: quan Pericó testà 26 de juliol de 1374, tant el seu pare com la seva muller eren vius i d'altra banda la tutoria no es podia perllongar més enllà del casament de Guillem (IX) el 27 de març de 1375; així i tot, aquests vuit mesos com a molt, devien resultar tempestuosos: durant 30 anys, fins al 1405, no hi hagué un acord sobre les despeses de la tutoria, que venia reclamant Guillem Sala, segurament descendent del tutor de Guillem, reclamació que aquest darrer any va ser desestimada en un arbitratge (perg. 818).
} 
Estolt, també de Sant Cebrià de Vallalta. ${ }^{36}$ La documentació d'aquesta època és escassa i difícil d'interpretar. No coneixem fills del primer matrimoni; del segon, Guillem tingué dues filles, Eulàlia i Margarida, que es devien portar molts anys: Eulàlia es va casar l'any 1403, mentre que Margarida no ho va fer fins més de vint anys més tard (perg. 804 i 918, respectivament) ${ }^{37}$. Però la filla gran, Eulàlia, no va ser cridada a la successió del mas ${ }^{38}$, que acabaria recaient en Margarida, que era encara menor d'edat en el moment del seu casament l'any 1424 (perg. 918).

El dot d'Eulàlia tampoc no l'aportaren els pares, sinó la seva tia-àvia Avinent Cortina. El lliurament es va fer a través de dos documents, tot dos datats el dia 5 d'abril de 1403: pel primer (perg. 805), Avinent Cortina, vídua d'Arnau Cabanya i fillastra de Guillem (VII), donà al seu nebot Guillem (IX) una casa i terres prop de l'església d'Arenys i una altra prop del mas de Bernat Miquel, béns que devien constituir en tot o en part el mas Cortina ${ }^{39}$, amb tres condicions principals: que Avinent en seria usufructuària de per vida, que Guillem havia de transferir la deixa a la filla Eulàlia com a dot, i que Avinent, Eulàlia i l'espòs d'aquesta viurien junts: sembla per tant que Avinent, vídua i sense ningú que tingués cura d'ella, s'afillà Eulàlia per a obtenir una família "normal". El document inclou encara una sèrie de clàusules amb alguna reserva de béns i la delimitació dels drets d'Avinent i Eulàlia si no poguessin conviure. El segon document són els capítols matrimonials d'Eulàlia, a qui Guillem (IX) dotà amb els béns que li acabava de cedir Avinent, béns que Eulàlia aportà en dot al seu matrimoni amb Bernat Tosell, d'Arenys (perg. 804). No sabem res més dels novells esposos; d'Avinent només que l'any següent (1404) Pere Cabanya, nebot i hereu d'Arnau Cabanya, li va fer reconeixement d'haver rebut d'ella el que li pertocava de l'herència del seu avi (perg. $816)$ i en un altre document renunciava a qualsevol reclamació posterior sobre aquesta (perg. 815).

Guillem (IX) afegia també altres ocupacions a la direcció del mas; així l'any 1393 liquidava amb el donzell Bernat de Riudeperes el producte de

\footnotetext{
${ }^{36}$ La identificació de Margarida Estolt prové dels capítols matrimonials de la seva filla Margarida (VIII) que cita el seu oncle matern Nicolau Vilar, àlies Estolt, entre els parents que consenten en el seu casament.

${ }^{37}$ De fet, tot i que el pergamí diu que Eulàlia era filla de Guillem i Margarida, es podria tractar d'un error de l'escrivent i que Eulàlia fos filla del primer matrimoni de Guillem.

${ }^{38}$ L'única explicació d'aquesta aparent anomalia és que el 1403 hi hagués un germà o una germana més grans i per tant amb millor dret a la successió, dels quals però no hi ha cap rastre documental. Eulàlia devia morir aviat, potser fins i tot abans del naixement de Margarida.

${ }^{39}$ Com hem vist, Bernat Cortina havia fet hereva del mas la mare Sança (perg. 612), de qui devia passar a la filla Avinent (Cabanya) i d'ella a Eulàlia Tria, de qui devia retornar al seu pare Guillem (VII) o directament a la germana Margarida, que en consta com a propietària l'any 1443 (perg. 1005).
} 
les rendes que aquest posseïa al terme del castell de Montpalau, que Guillem li administrava (perg. 744); en resultaren 25 florins ( 275 s.) a favor del donzell, que Guillem li posà en compte. D'altra banda l'any 1400, Guillem establí a Bernat i Vicenç Miquel, pare i fill, una peça de terra que tenia sota el domini eminent de Bernardí de Cabrera; l'establiment va ser pactat sense entrada, però a un cens de la cinquena part de la collita de cereals i la verema (de pane et vino) (perg. 791). Possiblement en aquest moment el mas Tria havia ja incorporat el mas Cortina i podia prescindir de terres més allunyades o de menor rendiment.

Guillem consta com a mort l'any 1414, i també ho havien de ser la seva esposa Margarida i la filla gran Eulàlia, atès que l'hereva Margarida estava sota la tutoria de Francesc Arquer, d'Arenys (perg. 871). De fet Margarida era encara menor d'edat el $1424^{40}$, quan es casà amb Joan Oliver, de Gascons d'Arenys, que aportà al mas 3.200 s. a part dels seus vestits i objectes personals: és la dotació més gran que he pogut documentar (perg. 918), però segurament el mas s'ho valia.

Del matrimoni de Joan (Oliver) Tria ${ }^{41}$ i Margarida (X) consten cinc fills i quatre filles. Les dues primeres filles es casaren molt joves: quan l'any 1447 Joana esposà el Jaume Mir, de Cabrera del Maresme, tenia setze anys i mig (perg. 1015 i 1016); i quan Elionor es casà el 1453 amb Gaspar Català de Mataró, en tenia quinze i mig (perg. 1038, 1039 i 1040), mentre que els marits en tenien respectivament divuit i vint. Totes dues reberen de dot $1.600 \mathrm{~s}$. i els complements acostumats; en canvi Joana només rebé d'escreix 400 s., mentre que Elionor n'obtingué 800. Una altra filla, Margarida, estigué casada amb Pere Vallori, de Sant Cebrià de Fuirosos, a qui aportà un dot de 1.400 s. a més de la caixa de núvia i els vestits. Margarida morí com a molt tard l'any 1458; la única notícia que tenim d'ella és un pergamí molt foradat (perg. 1075), que sembla que conté el compromís de Pere Vallori de retornar el dot. El document informa que el dot de Margarida s'havia pagat lliurant al futur espòs $600 \mathrm{~s}$. vint dies abans de les noces i prometent pagar-li $100 \mathrm{~s}$. més cada any fins a completar els $1.400 \mathrm{~s}$. Un termini de pagament tan llarg indica que el mas no passava un moment massa ufanós. Una darrera filla, Eulàlia, només és coneguda per la seva cita en el testament de Margarida l'any 1466.

El compromís de Pere Vallori va ser signat per Antoni Tria, heretat tot just quinze dies abans. En el seu heretament, la mare i propietària Margari-

\footnotetext{
${ }^{40}$ En aquest moment confessa que té més de quinze anys, però menys de vint-i-cinc (perg. 918).

${ }^{41}$ Com era habitual en els pubills, Joan Oliver prengué de seguida el nom del mas.
} 
da $(X)$ no hi inclogué el mas Estolt, de Sant Cebrià de Vallalta (perg. 1074) ${ }^{42}$, que llegà a un altre fill, que apareix com a Francesc Estolt en el testament del pare (perg. 1162). Antoni es casà amb una Margarida, de Sant Celoni, que aportà al mas un dot molt baix, només $300 \mathrm{~s}$. i en rebé 360 d'escreix. Antoni morí entre el 24 d'abril de 1465 (perg. 1108) i el 3 d'agost de 1466, data del testament de la seva mare (perg. 1113); la seva vídua es tornà a casar aviat amb Bernat Sala, paraire de Sant Celoni, que el 30 d'abril de 1467 firmà àpoca a Joan Tria i al seu fill Pere (XI) de la restitució del dot i l'escreix i d'una deixa de 200 s. que Antoni li havia fet en el seu testament (perg. 1120).

Com ha quedat dit, Margarida (X) va testar l'any 1466 (perg. 1113); llegà $20 \mathrm{~s}$. al marit, a qui fa a més usufructuari dels seus béns, i cinc sous a cada fill o filla vivent; tant Joana com Elionor com el primer hereu Antoni havien mort abans d'aquesta data, de manera que Margarida nomenà hereu el fill Joan, i establí l'ordre de successió amb Pere, Francesc, Jaume i Eulàlia; la novetat principal que conté el testament és la petició de les misses de Sant Amador $^{43}$. L'hereu Joan no li sobrevisqué gaire, havia mort abans del 14 de febrer de 1467 (perg. 1117), data en la que consta com a hereu el seu germà Pere (XI). Joan (X) testà l'any 1475 , amb unes clàusules semblants a les del testament de la seva esposa (perg. 1162): demanà també que es celebressin les misses de Sant Amador, per les que pagà 33 s.; així mateix manà que es destinés una quartera de blat per a fer pa per als pobres els dies de la novena i cap d'any; deixà $5 \mathrm{~s}$. a cada fill i a cada nora i es recordà també dels seus néts. Finalment ordenà que el fill solter, Jaume, fos dotat segons les possibilitats del mas (perg. 1162) 44; $^{4}$ la filla Eulàlia devia haver mort abans, atès que no se'n fa cap menció.

Joan i Margarida Tria (X) estigueren al davant del mas durant més de quaranta anys, però no sabem gairebé res de la seva actuació: el mas Cortina i el mas Estolt els van sobrevenir i ja hem vist que si el 1447 i el 1453 els dots de Joana i Elionor es van pagar sense dificultats, cinc anys més tard, el dot de Margarida va ser inferior i pagat amb llargs terminis. Mentrestant només coneixem la lluïció, feta l'any 1443, un cens de 2 s. i 6 d. que Narcís Benaiges cobrava sobre quatre peces de terra del mas Cortina, lluïció que costà $40 \mathrm{~s}$. (perg. 1005). En canvi sembla que les devastacions i l'augment de la pressió

\footnotetext{
${ }^{42}$ El mas Estolt havia d'haver pervingut a Margarida $(X)$ a través de la seva mare, que al seu torn el devia haver heretat del seu germà Nicolau (perg. 918).

${ }^{43}$ Les misses de Sant Amador són un trentenari de misses a dir a partir dels dies següents a la mort amb la finalitat de treure de pressa l'ànima del difunt del purgatori; es van popularitzar molt a partir del final del segle XIV, tot i rebre severes critiques; sant Vicenç Ferrer, per exemple, les considerava una pràctica simoníaca, Cerdà 2006.

${ }^{44}$ Aquest era un canvi substancial respecte als cabalers anteriors: representava que Jaume seria dotat aproximadament igual que les noies que sortien del mas per a casar-se.
} 
fiscal que acompanyaren la guerra civil de 1462-1472 i la seva postguerra permeteren als masos benestants adquirir terres d'altres més dissortats. Així, el mas Tria comprà l'any 1466, per 60 s., un tros de terra prop del mar, de 32 per 16 canes de Montpeller ${ }^{45}$, part d'una peça més gran, tinguda pel mas Cruanyes a un cens que no s'indica; els venedors foren Eulàlia, vídua de Jordi Domingo, i del seu fill Jaume, (perg. 1108); la terra es carregà amb un cens de $3 \mathrm{~s}$. anuals a favor dels venedors, com a ajuda del cens que els Domingo feien per tot el tros al mas Cruanyes, que n'era per tant el senyor directe. Els venedors fan constar a més a més que la venda està subjecta a lluïsme, firma i fadiga en favor del senyor directe del castell de Sant Pol de Mar.

Pere (XI), hereu definitiu de Joan i Margarida, esposà el 14 de febrer de 1467 Joana Sala, d'Arenys ${ }^{46}$, la qual li aportà un dot de 1.200 s., amb pacte de tantumdem ${ }^{47}$, al qual Pere afegí a més una donació de $300 \mathrm{~s}$. de lliure disposició, la mateixa quantitat que el dot reservava a Joana per a testar (perg. 1117). Joana Sala era viva quan testà Joan Tria (X) l'any 1475 (perg. 1162), però el 1481 Pere apareix casat amb Eulàlia Teixidor, de Pineda ${ }^{48}$. Com veurem, ambdues li donaren fills. Pere (XI) tingué el mas Tria en el moment de pas de l'edat mitjana a l'edat moderna i visqué fins més enllà de 1520; la seva és per tant la darrera generació del mas Tria de que estudiarée ${ }^{49}$. L'any 1488 Pere dotà el seu germà Jaume, que rebé $1.200 \mathrm{~s}$. i els seus vestits i objectes personals a l'hora del seu casament amb Eulàlia Vilar, de Sant Cebrià de Va-

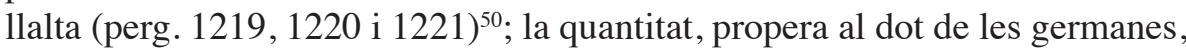
significa un canvi d'actitud respecte la migradesa de les dotacions dels fadristerns del segle XIII.

Pere (XI) continuà la política de compra dels seus pares: l'any 1477 adquirí d'Angelina, vídua de Bartomeu Amar, i el fill d'aquests Bernat una peça de terra erma i boscosa (perg. 1169), segurament gran però abandonada de temps: havia de ser gran, perquè Pere Tria en pagà 100 s., i abandonada perquè l'establiment s'havia fet a tasca i braçatge, cens que evidentment els Tria

\footnotetext{
${ }^{45}$ La cana de Montpeller feia 1,98 m, Alsina, Feliu, Marquet 1990, pp. 131-132; per tant el tros feia $2.007,25 \mathrm{~m}^{2}$.

${ }^{46}$ En els capítols matrimonials Margarida confessa ser menor de vint-i-cinc anys, però major de setze.

${ }^{47}$ El pacte de "tantundem" (en realitat de "tantundem ... quantundem") exigia que l'escreix tingués el mateix muntant que el dot; es generalitzà a final de l'edat mitjana i va ser gairebé norma en els capítols matrimonials posteriors.

${ }^{48}$ Aquest any Eulàlia renunciava als seus drets a l'herència paterna i materna a canvi del seu dot, el pagament del qual s'allargassà molt: el 1489 Pere Tria feia àpoca al seu sogre per $1.000 \mathrm{~s}$. que havia rebut del dot de la seva esposa, Pons i Guri, Rodríguez 1990, doc. 575 i 589.

${ }^{49}$ La família perdurà fins a l'any 1644 , quan per casament de la pubilla Mariàngela Tria amb Josep M. Jalpí, es fongué amb aquesta, Pons i Guri 1982, p. 15.

${ }^{50}$ Jaume havia mort abans del 30 d'abril de 1518 (perg. 1375).
} 
van haver de continuar pagant. La segona compra fou feta l'any 1485 a Margarida Pertegaç, representada pel seu fill Galceran Alsina (perg. 1210); es tractava d'una peça de terra també erma, al Puig de Palom, per la quan Pere Tria pagà 40 sous $^{51}$.

Fills del matrimoni de Pere (XI) amb Joana Sala foren Joan, Eulàlia i Angelina, esmentats en el testament de l'avi Joan (X), de l'any 1475 (perg. 1162); però no es coneix cap menció documental posterior de cap d'ells. Nascuda més tard d'aquest testament devia ser Joana, que no hi és esmentada, i que es casà l'any $1500 \mathrm{amb}$ Pere Lleu, d'Arenys, amb un dot de $800 \mathrm{~s}$., una caixa de núvia i un parament de llit, amb pacte de tantumdem (perg. 1278). Del segon casament de Pere (XI) amb Eulàlia Teixidor se'n coneix un únic fill i hereu, Gabriel (perg. 1291), i quatre filles. Gabriel Tria (XII) va ser heretat l'any 1503 (perg. 1291), tot i que no es va casar fins l'any 1508 amb Caterina Gibert, filla d'Hipòlit Pujades (a) Gibert i d'Eulàlia, difunta, que havia estat propietària del mas Gibert de Torrentbò (perg. 1322 -1324); Caterina aportà un dot de $1.800 \mathrm{~s}$. amb pacte de tantundem (perg. 1322). De les filles, Caterina, esposà abans de 1504 Bartomeu Puig, d'Arenys, amb un dot de $1.000 \mathrm{~s}$. a més dels vestits i la caixa de núvi acostumats ${ }^{52}$. La resta de germanes es van casar: Francina l'any 1516 amb Nicolau Puig, de Sant Genís de Palafolls (perg. 1371 i 1372); Margarida, l'any1520 amb Joan Teulada, de Pineda; i Elisabet l'any 1522 amb Bartomeu Galceran de Canyamars, batlle del castell de Montclús (perg. 1396). El dot de totes elles va ser de $1.600 \mathrm{~s}$. amb els afegits dels vestits ordinaris i la caixa de núvia i amb pacte de tantundem $^{53}$. Pere Tria (XI) era viu en el moment del casament de Margarida, però consta com a mort en el d'Elisabet: va morir doncs entre 1520 i 1522.

\section{ELS TRIA, REMENCES I SENYORS DE REMENCES}

L'estudi de la família Tria es justifica per la seva condició de remences a la vegada senyors de remences. Des de quan? No consta que fossin remences els primers representants coneguts de la família, ni Ramon (I), ni Berenguer Dois i Guillema (II) ni Ramon (III) i la seva esposa Cristiana; o

\footnotetext{
${ }^{51}$ El regest diu que Galceran Alsina era l'espòs de Margarida, però en el text queda clar que l'espòs d'aquesta era Gabriel, pare de Galceran.

${ }^{52}$ Només coneixem l'àpoca de renúncia a l'herència, de manera que desconeixem la contraprestació oferta pel marit, però en aquesta època ja s'havia generalitzat el pacte de "tantundem" (perg. 1300).

${ }^{53}$ En el cas de Margarida, tant els capítols matrimonials com l'àpoca de renúncia a l'herència contenen una relació dels vestits nupcials: "unam gonellam, unum roponem et unum mantellum nuptiales" (perg. 1383 i 1384).
} 
sigui no consta que el mas fos remença gairebé durant tot el segle XIII. De fet, la primera notícia segura de que els Tria eren remences és la redempció gratuïta de Sança, filla de Ramon (V) l'any 1310 (perg. 206), però és molt possible que Ramon (V) ho fos ja com a mínim l'any 1295, quan signà com a batlle d'Arenys en l'establiment d'un honor que els Tria van fer a Guillem Soler i la seva esposa Guillema (perg. 148) ${ }^{54}$. L'establiment és pràcticament coetani a la substitució dels Montclús pels Cabrera en la baronia de Montclús, en la persona de Ramon de Cabrera, senyor d'Anglès i Brunyola (perg. 148), el qual bé podia haver canviat el batlle anterior i nomenar en el seu lloc Ramon Tria (V), previ jurament per part d'aquest de fer-se home propi, soliu, afocat i de remença seu. Que el primer batlle i per tant segurament el primer remença de la família fou Ramon (V) i no el seu pare Pere (IV) ho corrobora el fet que a l'hora de signar l'establiment citat ho fessin primer els pares, Pere i Avinent, seguits pel fill heretat Ramon $(\mathrm{V})$, que acte seguit tornà a signar com a batlle d'Arenys ${ }^{55}$; indirectament ho mostra també que Ramon de Cabrera enfranquís gratuïtament Sança, filla de Ramon (V) propter multa grata servicia et ydonea que dictus pater tuus nobis fecit et cotidie facere conatur (perg. 206).

Gairebé al mateix temps que es sotmetien com a remences, els Tria es devien convertir també en senyors de remences: com ja ha quedat dit, l'establiment que ens ocupa es fa a condició que els Soler hi construeixin un mas, l'habitin, el tinguin afocat $\mathrm{i}$ el deixin a un fill que igualment el mantingui afocat ad servicium et fidelitatem nostram; no és del tot segur que aquestes condicions els convertissin en remences, però poc se'n podia faltar. El dubte neix de que es fa constar expressament que l'establiment no estarà subjecte a cap altre cens, agrer ni usatge més que mitja quartera de blat a mesura de Sant Celoni, un parell de gallines per Nadal i tasca i braçatge de totes les collites (perg. 148); es podia tractar per tant d'un mas afocat però no de remença.

Fos com fos, els Tria consten clarament com a senyors de remences l'any 1303, quan els esposos Guillem Llobet i Elisenda, d'Arenys, reconeixen Ramon (V) i la seva esposa Avinent com a senyors naturals i es confessen homes propis i solius seus, sense que deixin de ser-ho pel fet d'anar a viure a Barcelona i sense comprometre's a pagar cap cens com a reconeixement de la seva condició de remences (perg. 174).

Ens ha arribat només una part petita de la documentació que devien generar els pagaments i cobraments dels Tria com a remences i senyors de

\footnotetext{
${ }^{54}$ Sobre la vinculació de la concessió de la batllia a la tinença d'un mas i al reconeixement del batlle de home propi i soliu seu i ocupant del mas, o sigui, remença, Martínez Giralt 2012, p. 74; Benito 2012 p. 6.

${ }^{55}$ Estranyament aquesta signatura del batlle no figura en cap altre dels pergamins examinats.
} 
remences, tota ella referent a redempcions o reconeixements de senyoria, tot $\mathrm{i}$ que sens dubte es van generar com a mínim eixorquies. L'única excepció és la menció d'una firma d'espoli (perg. 593) $)^{56}$.

Comencem pels documents que demostren que el mas Tria i els seus habitants eren homes propis, solius i de remença dels Cabrera, senyors del castell de Montclús i dels seus successors. Ja m'he referit a l'enfranquiment gratuït de Sança, filla de Ramon Tria (V); en canvi cinc anys més tard la redempció de la seva germana Agnès costà al mas 80 s. (perg. 237). La condició de remences dels Tria no torna a estar documentada fins més de mig segle més tard, l'any 1370, i aquesta vegada afecta el casament de l'hereu: l'entrada al mas de Sança Bosch, casada amb Pericó Tria (VIII), costà 100 s. en concepte de firma d'espoli, quantitat en la que s'avingueren el pare de Pericó, Guillem Tria, i l'administrador del vescomtat, en aquell moment segrestat pel rei (perg. 593). Els següents documents d'enfranquiment que s'han conservat són molts anys més tardans, però relativament propers entre ells: el 27 d'octubre de 1447, Antoni Ferrer procurador substitut de Violant de Cabrera, consort i procuradora de Bernat Joan de Cabrera, redimí Joana, filla de Joan Tria i Margarida (X), a canvi de 77 s.; i el 5 d'abril de 1453 el mateix procurador enfranquí Elionor, germana de Joana, per 55 s. (perg. 1017 i 1038). No puc donar cap explicació a aquesta diferència: les dues germanes van rebre el mateix dot i d'escreix Joana en va rebre el doble que Leonor ${ }^{57}$. Més important em sembla assenyalar que el preu de les redempcions es mostra estable durant tot el temps estudiat, més aviat amb una lleugera tendència a la baixa.

Les notícies dels Tria com a senyors de remences són més, i més explicatives. Ja m'he referit a l'establiment fet l'any 1295 als esposos Guillem Soler i Guillema i al reconeixement fet l'any 1303 pels esposos Guillem Llobet i Elisenda (perg. 148 i 174). Un altre document de l'any 1332 (perg. 312) ens informa d'una situació semblant: Bernat Riera, de Premià, reconeix que és home propi i soliu de Pere (IV) i li promet que no tindrà altre senyor; i, aspecte que no consta en el document anterior, li promet a més a més que, en reconeixement del seu domini, li pagarà un sou cada any ${ }^{58}$.

La major part dels documents conservats dels Tria actuant com a senyors de remences es concentren en els anys 1373-1374 i és en aquests que es troba la tipologia més corrent de reconeixement de remença, com en la prestació d'homenatge feta l'any 1373 per Jaume Puig, d'Arenys, que es fa home

\footnotetext{
${ }^{56}$ Convé també assenyalar que, tot i que Arenys pertanyia al bisbat de Girona, les redempcions de les dones solteres sobrepassen de molt els 2 s. 8 d. que Mieres, en la seva recopilació dels costums de Girona, assenyalava com a tarifa per a les donzelles, Cobos 2001, p. 57.

${ }^{57}$ Un cas semblant és reportat per Lluch 2005, p. 236.

${ }^{58}$ Casos semblants són documentats per ibidem, p. 91.
} 
propi i soliu de Guillem Tria (IX) per la borda anomenada can Llobet (perg. 620). Puig afirma que és lliure i deslligat de tot domini senyorial ${ }^{59}$ i com que no diu que l'entrada a la borda es produeixi per matrimoni, o bé Puig n'havia esdevingut propietari com a hereu d'algun parent, o bé es tractava d'una borda nova o que havia retornat al mas Tria per manca de conreadors (havia esdevingut rònega); en qualsevol d'aquests dos darrers casos, els Tria en farien un nou establiment a Puig ${ }^{60}$. Fos com fos, aquest fa l'acostumat jurament de fidelitat i homenatge i jura també que no entrarà en cap lloc privilegiat que pugui fer perdre al senyor els seus drets damunt d'ell.

Pel que fa als quatre documents de l'any 1374, fan referència només a dos casos, en cadascun d'ells amb un document per a cada cònjuge: Pere Fossas, de Llinars, es fa home propi i soliu de Pere Tria (VIII) per una borda el nom de la qual manca al document, que però indica in qua vos habetis homines et feminas, amb els juraments acostumats de fidelitat i homenatge i de no marxar a lloc privilegiat (perg. 626); la raó és el seu casament amb Avinent Salvador, d'Arenys, la qual dos dies més tard reconeix a Pere Tria que és dona pròpia seva (perg. 628). Els altres dos documents calquen el mateix procés, si bé ara és la dona la que entra a viure al mas: Bernat Domingo reconeix al mateix Pere Tria que és home propi i soliu seu, amb els juraments acostumats (perg. 627), i el mateix dia la seva esposa Geralda, es fa dona pròpia del dit Pere per poder entrar a la borda del seu marit (perg. 629).

No s'ha conservat cap més noticia dels Tria com a senyors de remences fins a l'agost de 1414, quan Jordi Colomer, àlies Domingo, es fa home propi i soliu de Francesc Arquer, tutor de Margarida (VIII), filla i hereva de Guillem de Trilla, a causa de la seva entrada al mas Domingo pel seu casament amb Eulàlia, pubilla d'aquest mas (perg. 870). El reconeixement d'aquesta es demorà més de cinc mesos i en ell Eulàlia feia constar que era menor de vinti-cinc anys però major de quinze, raó per la qual renunciava a qualsevol privilegi per raó de ser menor d'edat (perg. 875); l'explicació més normal d'aquest retard és que a l'agost Eulàlia no tingués ni quinze anys.

Que els Tria eren senyors de remences ho deixa ben clar la fraseologia utilitzada en els documents:

recognosco me fore hominem solidum et proprium vestri (perg. 312)

\footnotetext{
${ }^{59}$ Això no significa que no pogués haver estat remença sota un altre domini; només que, en aquest supòsit, s'hauria redimit prèviament.

${ }^{60}$ La submissió a la remença a canvi d'obtenir la borda havia de figurar en l'establiment, que no ens ha pervingut, però es doblava amb aquest document d'acceptació per part del nou propietari del domini útil.
} 
evenio et facio me hominem proprium et solidum vestri (...) una cum omni prole mea (...) racione borde mee (perg. 620)

evenio et facio me hominem proprium et solidum (...) quia intratus sum et uxorem duxi bordam vocatam in qua vos habetis homines et feminas (num. 626)

recognosco (...) quod sum et ese debeo femina propia et solida (...) ut heredis dicti mansi mei vocati Domingo quod (...) tenetur sub perceptione hominum et mulierum et servitutum ipsorum, qui ipsum mansum condirectum teneant casatum et etiam affocatum (doc. 875).

La doble condició dels Tria i altres casos semblants, a la vegada remences i senyors de remences, em porta a la conclusió de que la remença era una situació jurídica, però no social (no sembla que dificultés el casament amb no remences) ni encara menys econòmica: fins $i$ tot es documenten alguns remences que posseïen esclaus ${ }^{61}$.

\section{ELS TRIA, BATLLES D’ARENYS}

Segons l'heretament de Pericó (VIII), la batllia proporcionava a la família censos, rèdits $i$ altres ingressos ${ }^{62}$. Encara que les notícies són escasses, no hi ha dubte que els Tria mantingueren sempre el càrrec: quan el 1373 el rei retornà a Bernat IV de Cabrera el vescomtat que havia segrestat com a consequiència del procés i l'execució del seu avi Bernat II, el comte ${ }^{63}$ va ratificar a Guillem de (VII) i els seus descendents la possessió de la batllia natural d'Arenys (perg. 624), però això no vol dir que no l'haguessin mantingut durant el segrest, encara que fos en nom del rei. Només quan a la mort de Guillem (IX) i Margarida el mas va quedar en mans de la seva filla Margarida, menor d'edat, el comte va nomenar un regent de la batllia: el 1414 exercia el càrrec Pere Puig. Amb el casament de Margarida (X) l'any 1424, la batllia retornà al mas: el seu espòs Joan consta com a batlle en diversos documents. Tot i que a Arenys hi havia una altra família de batlles, els Sala, que ho eren del monestir de Sant Pol ${ }^{64}$, només els Tria eren batlles jurisdiccionals.

${ }^{61}$ Codina 1990; Richou 2012,p. 149; Lluch 2014, p. 176.

62 "censos, redditus et proventus" (perg. 568).

${ }^{63}$ Vescomte de Cabrera i comte de Mòdica, a Sicília, títol pel qual era conegut.

${ }^{64}$ Els Tria i els Sala emparentaren com a mínim dues vegades, pel casament de Ramon (V) amb Avinent Sala (1293) i pel de Pere (XI) amb Joana Sala (cap a 1466); i possiblement dues més: la conflictiva tutoria de Guillem (IX) per part d'un membre de la familia Sala (1374-1375) havia de respondre a algún grau de parentiu (perg. 818); i el 1424 Margarida (X) afirma que 
Per desgràcia, els pergamins relacionats amb l'actuació dels Tria com a batlles d'Arenys són molt escassos: ja m'he referit a la primera menció com a batlle de Ramon (V), l'any 1295 (perg. 148). No n'hi ha cap altra notícia fins que el 1354, unes paus entre dos grups familiars enfrontats i el jurament de mantenir-les i fer-les jurar als descendents s'establiren davant de Guillem (VII) com a batlle d'Arenys, (perg. 475). Un altre document de l'any 1364, en molt mal estat, ens informa que el mateix Guillem (VII) pagà 50 s. a Berenguer de Malla, procurador de Bernat III de Cabrera, comte d'Osona, però no és possible llegir la raó del pagament (perg. 554), segurament una liquidació de comptes. Mig segle mes tard, Francesc Arquer, com a tutor de Margarida (X), pagà $220 \mathrm{~s}$. a Pere Puig, batlle substitut, a compte d'una major quantitat resultant del passament de comptes de temps de Guillem (IX), pare de Margarida (perg. 871). Finalment coneixem l'auditoria dels comptes de la batllia de l'any 1428: el resultat foren uns ingressos a favor del comte de $4111.11 \mathrm{~s} . \mathrm{i} 4 \mathrm{~d}$., però unes despeses de $4111 ., 18 \mathrm{~s}$. i 4 d. (perg. 935); com que el comte havia hagut de pagar el procurador i els auditors, el negoci feudal resultava, com a mínim en aquest cas, un mal negoci. És la darrera notícia que he pogut recollir dels Tria com a batlles d'Arenys ${ }^{65}$.

\section{CONCLUSIONS}

El punt més important d'aquest repàs a la història del mas Tria i els seus propietaris és sens dubte el fet de ser a la vegada remences i senyors de remences; no es tracta pas d'una anècdota, sinó d'una categoria: demostra d'una banda que la servitud remença era compatible amb la posició de pagesos benestants, cosa ja sabuda, i d'una altra que la remença no era una servitud en el sentit clàssic del terme sinó una situació jurídica que comportava aspectes servils i constriccions econòmiques, però que no significava cap segregació ni impedia l'enriquiment ni l'ascens social. Secundàriament la documentació permet afirmar també que al Maresme dels segles XIV i XV, el cost de la remença es va mantenir estable i més aviat a la baixa, en contraposició al clar creixement del muntant dels dots.

La batllia, que la documentació permet estudiar molt poc, a part d'ingressos econòmics, comportava sens dubte una certa ascendència sobre la població, que redundava en el prestigi del mas ${ }^{66}$.

es casa amb consentiment, entre altres, de Bernat Sala, parent seu, segurament casat amb una germana de la seva mare (perg. 918).

${ }^{65}$ L'examen dels llibres de la batllia podria oferir més dades, però requeriria una investigació nova i un espai que superaria de molt el disponible.

${ }^{66}$ Benito 2012. 
L'evolució de la família durant dotze generacions al llarg dels segles XIII-XV proporciona un bon exemple de l'evolució d'un mas ric, de les seves possibilitats, relacions i problemes que afrontava. Tot i que es tracta només d'un cas, voldria posar de relleu el gran nombre de fills adults a final del segle XIII i començament del XIV (generació V) i altra vegada al segle XV (generacions XI i XII), en contrast amb les dificultats de la segona meitat del segle XIV.

La documentació no permet fer-se una idea gaire precisa de l'evolució econòmica del mas, però sí que ofereix bons exemples de compres, d'establiments, subestabliments i arrendaments. A primera vista sembla que el mas Tria no ven mai, però convé recordar que a qui li interessa conservar un document de venda és al comprador, no al venedor.

Per acabar voldria assenyalar que l'estudi més aprofundit del dots i els testaments i la seva evolució aporta coneixements diversos i molt interessants, però l'espai disponible m'han dissuadit d'entrar en el tema.

\section{BIBLIOGRAFIA CITADA}

Alsina, Claudi; Feliu, Gaspar; Marquet, Lluís (1990), Pesos, mides i mesures dels Països Catalans, Barcelona, Curial.

Aventín i Puig, Mercè (1996), La societat rural a Catalunya en temps feudals, Vallès oriental, segles XIII-XVI, Barcelona, Columna.

Benito i Monclús, Pere (2012), Élites rurales et intermédiaires de la seigneurie en Catalogne (XII ${ }^{e}-X I V^{e}$ siècle), "Mélanges de l’École Française de Rome - Moyen Âge" [en línea] 124/2 DOI: 10.4000/mefrm.874.

Cerdà Subirachs, Jordi (2006), Les misses de Sant Amador, purgatori i cultura popular, Barcelona, Publicacions de l'Abadia de Montserrat.

Cobos Fajardo, Antoni (ed. i trad.) (2001), Costums de Girona, [compilació] de Tomàs Mieres, Girona, CCG Edicions.

Codina, Jaume (1990), Els santboians de 1490. Com es vivia fa 500 anys a la vila de Sant Boi de Llobregat, Barcelona, Publicacions de l'Abadia de Montserrat.

Feliu i Montfort, Gaspar (2011), Rellegint la Història dels remences, de Jaume Vicens Vives, "Butlletí de la Societat Catalana d'Estudis Històrics" 22, pp. 33-64.

Fernández Trabal, Josep (2002), El conflicte remença a la Catalunya del segle XV (1388-1486), "Afers: fulls de recerca i pensament" 42/43, pp. 587-624.

Freedman, Paul H. (1993), Els orígens de la servitud pagesa a la Catalunya medieval, Vic, Eumo (ed. original 1991). 
Lluch Bramon, Rosa (2004), Les viles medievals. Franqueses i mals usos, "Butlletí de la Societat Catalana d'Estudis Històrics" 19, pp. 9-28.

Lluch Bramon, Rosa (2005), Els remences. La senyoria de l'Almoina de Girona als segles XIV i XV, Girona, Documenta Universitaria.

Lluch Bramon, Rosa (2014), Remences pauvres, remences riches: les inégalités économiques (Vieille Catalogne, XIV-XVI), en Cavaciocchi, Simonetta (ed.), Schiavitù e servaggio nell'economia europea. Secc. $X I-X V I I I=$ Serfdom and Slavery in the European Economy. $11^{\text {th }}-18^{\text {th }}$ Centuries: atti della "Quarantecinquesima settimana di studi", 14 18 aprile 2013, Florència, Firenze University Press, pp. 173-184 (Atti delle "Settimane di Studi" e altri Convegni; 45).

Marcó Masferrer, Xavier (2008), La diferenciació pagesa a la Catalunya baixmedieval: la revisió del cas de la vall d'Aro, "Estudis d'Història Agrària" 21, pp. 125-149.

Martínez Giralt, Alejandro (2012), El poder feudal, els seus agents i el territori. El vescomtat de Cabrera (1199-1423), Santa Coloma de Farners, Centre d'Estudis Selvatans (estudis i textos; 15 ).

Ortí i Gost, Pere; To Figueras, Lluís (2014), Serfdom and Standard of Living of the Catalan Peasantry before and after the Black Death of 1348 en Cavaciocchi, Simonetta (ed.), Schiavitù e servaggio nell'economia europea. Secc.XI-XVIII = Serfdom and Slavery in the European Economy. $11^{\text {th }}-18^{\text {th }}$ Centuries: atti della "Quarantecinquesima settimana di studi", 14-18 aprile 2013, Florència, Firenze University Press, pp. 155-169 (Atti delle "Settimane di Studi" e altri Convegni; 45).

Pons i Guri, Josep Maria (1982), Arxiu Històric Fidel Fita d'Arenys de Mar, dins Guia dels Arxius Històrics de Catalunya, Barcelona, Departament de Cultura de la Generalitat de Catalunya, vol. 1, pp. 7-33.

Pons i Guri, Josep Maria (1984), Inventari dels pergamins de l'arxiu històric Fidel Fita d'Arenys de Mar, Barcelona, Departament de Cultura de la Generalitat de Catalunya.

Pons i Guri, Josep Maria (1989a), Un cartoral de la Milícia Hospitalària, dins Pons i Guri, Josep Maria, Recull d'estudis d'Història Jurídica Catalana, Barcelona, Fundació Noguera, vol. III, pp. 416-436 (Textos i Documents; 22), reedició de Pons i Guri, Josep Maria (1962), Un cartoral de la Milícia Hospitalària, "Circular n. 14 (setembre 1962) de l'Arxiu Històric Fidel Fita".

Pons i Guri, Josep Maria (1989b), Nous documents de la comanda hospitalària de Sant Celoni, dins Pons i Guri, Josep Maria, Recull d'estudis d'Història Jurídica Catalana, Barcelona, Fundació Noguera, vol. III. pp. 437-457 (Textos i Documents; 22), reedició de Pons i Guri, Josep 
Maria (1964) Nous documents de la comanda hospitalària de Sant Celoni, "Circular n. 18 de l'Arxiu Històric Fidel Fita".

Pons i Guri, Josep Maria (2002), Hostalric, capital i arxiu del Vescomtat de Cabrera, "Quaderns de la Selva" 14, pp. 7-20.

Pons i Guri, Josep Maria; Rodríguez Blanco, Jesús (1990), Inventari dels Pergamins de l'Arxiu Històric Municipal de Calella, Barcelona, Fundació Noguera (Textos i Documents; 23).

Richou i Llimona, Montserrat (2012), La terra, la familia i la mort al Baix Maresme (1348-1486), Barcelona, Fundació Noguera (Estudis; 62).

Vicens Vives, Jaume (1945), Historia de los remensas en el siglo XV, Barcelona, Consejo Superior de Investigaciones Científicas, Instituto Jerónimo Zurita.

Vicens Vives, Jaume (1954), El Gran Sindicato Remensa (1488-1508). La última etapa del problema agrario catalán durante el reinado de Fernando el Católico, Madrid, Consejo Superior de Investigaciones Científicas, Patronato Marcelino Menéndez y Pelayo.

Fecha de recepción del artículo: enero 2017

Fecha de aceptación y versión final: octubre 2017 